\title{
Kurumsal Kalite Doğrudan Yabancı Yatırımlar İçin Ne Kadar Önemli? Türkiye Üzerine Ekonometrik Bir Analiz ${ }^{*}$
}

\author{
How Important is Institutional Quality for Foreign Direct Investment? \\ An Econometric Analysis on Turkey
}

\author{
Şerife ÖZŞAHIN, Necmettin Erbakan Üniversitesi, Türkiye, sozsahin@konya.edu.tr
}

\begin{abstract}
Öz: 1990'lı yıllarla birlikte ekonomik kalkınma üzerine yapılan pek çok çalıșmada, ülkeler arası gelişmişlik farkının kurumsal faktörlerden kaynaklanacağl dile getirilmiştir. Bu bağlamda kişisel haklar, yolsuzluk, bürokratik kalite, siyasi özgürlük gibi kurumsal kalite göstergeleri ile ekonomik risk düzeyi, özellikle kalkinma yolundaki ülkelerin dış yatırımları çekebilmesi ve bu doğrultuda büyüme hedeflerini yakalaması açısından çok önemli hale gelmiştir. Türkiye'de kurumsal kalite ve ekonomik risk düzeyinin doğrudan yabancl yatırım hacmi ve oynaklığl üzerindeki etkisinin araştırıldığ bu çalışmada, sinır testi ve gecikmesi dağıtılmış otoregresif model (autoregressive distributed lag-ARDL) yardımıyla 3 farkl eşitlik tahmin edilmiştir. Yapılan ekonometrik analiz sonucunda daha kaliteli kurumsal yapı ve düşük ekonomik risk düzeyinin ülkeye gelen doğrudan yabancı yatırım hacmi üzerinde pozitif yönlü etkiye sahip olduğu bulgusuna ulaşllmıştır. Çallş̧manın bir diğer önemli bulgusu ise yüksek kurumsal kalite düzeyinin ülkeye gelen doğrudan yabancı yatırımların oynaklı̆̆ı üzerindeki azaltıcı etkisidir.
\end{abstract}

Anahtar Sözcükler: Doğrudan Yabancı Yatırım, Kurumsal Kalite, Türkiye, ICRG, Sinır Testi ve ARDL Yöntemi.

Abstract: With the 1990's, studies on economic development have emphasized institutional factors explaining the difference between states. In this context, property rights, corruption, bureaucratic quality, political rights have became crucial for developing countries which aim to foreign investment and thereby achieve growth target. In this study, three equations were estimated by using bound test and ARDL method in order to understand the impact of institutional quality and economic risk level on volume and volatility of foreign direct investment. According to results of the analysis, it is found that there is a positive relationship between the high institutional quality, low level of economic risk and foreign direct investment inflow. Another important finding of the study is that a high level of institutional quality has a diminishing effect on foreign direct investment volatility.

Keywords: Foreign Direct Investment, Institutional Quality, Turkey, ICRG, Bound Test and ARDL Method.

\section{Giriş}

1990’lı yıllarla birlikte ekonomik gelişmişlik üzerine yapılan çalışmaların pek çoğunda kurumsal faktörlerin önemine daha fazla vurgu yapılmaya başlanmıştır. Teorik altyapısını Solow (1956)'nın oluşturduğu geleneksel neo-klasik büyüme modellerinde ülkeler arası gelişmişlik farkının tasarruf oranları ve faktör birikimlerinden kaynaklandığı belirtilmiş ancak kurumsal faktörlerin farklı büyüme oranları üzerindeki etkisine hiç değinilmemiştir. Lucas (1988), Romer (1986, 1990), Grossman ve Helpman (1991), Aghion ve Howitt (1992)'nin katkılarıyla şekillenen içsel büyüme modelleriyle birlikte yenilik, ölçek ekonomileri, sermaye birikimi ve eğitim gibi kavramlar daha sık vurgulansa da North ve Thomas (1973), bu faktörleri büyümenin sebebi olarak değil büyümenin kendisi olarak görmüşlerdir. Bu doğrultuda ülkeler arası büyüme oranlarında farklılık yaratan en temel neden ise kurumsal yapıdaki farklılıklardır (Acemoğlu vd., 2005: 388).

Ekonomik performans farklılıkları üzerine yapılan dikkat çekici bir diğer çalışma ise Hall ve Jones (1999) tarafından kaleme alınmıştır. Bu çalışmada, ABD’nin Nijerden 35 kat daha fazla işçi başına çıktı üretmesinin ve Nijer'de bir işçinin tüm yıl boyunca yapacağı üretimin Amerikalı bir işçi tarafından nasıl 10 günde yapıldığının sebepleri sorgulanmıştır. Ülkeler arası gelişmişlik farkını fiziki ve beşeri sermaye düzeyi ile verimliliğe dayandıran görüşlere ilave olarak Hall ve Jones (1999), sorunun kaynağına inerek hangi faktörlerin ülkeler arası sermaye birikimini ve verimliliği farklılaştırdığını sorgulamıştır. Bu doğrultuda, kurumlar ve hükümet politikalarındaki farklılıkların şekillendirdiği "sosyal altyapının", ekonomik çerçeveyi biçimlendirerek ekonomik aktörlerin sermaye birikimi ve yatırım kararları üzerinde etkide bulunduğuna değinmişlerdir (Hall ve Jones, 1999: 84).

Tüm bunlara paralel olarak ülkedeki kurumsal yapının, ülkeler arası sermaye hareketlerinin en istikrarlı yapıya sahip şekli olan doğrudan yabancı yatırımlar aracılığıyla ev sahibi ülkede verimlilik artışlarını beraberinde getireceğine dair literatürde yaygın bir kabul vardır. Ev sahibi ülkede kurumsal kalitesi yüksek yapıların varlığı, özellikle yabancı yatırımcılar için belirsizliği azaltacağı ve bu doğrultuda getiri oranını yükselteceği için iyi bir yatırım ortamının tesis edilmesine yardımcı olacaktır (Benassy-Quere vd., 2007: 764). Kurumların belirsizliği azaltmak suretiyle

\footnotetext{
${ }^{*}$ Bu çalışma, 10-12 Haziran 2015 tarihlerinde Anadolu Üniversitesi tarafindan düzenlenen EconAnadolu 2015 Uluslararası Konferansında sunulan bildirinin gözden geçirilmiş ve yeniden düzenlenmiş halidir.
} 
makroekonomik istikrara yapacağı katkının yanısıra ekonomiyi dışsal şoklara karşı daha sağlam bir yapıya kavuşturması da elde edilecek bir diğer önemli kazanımdır (Uğur, 2011: 39).

Türkiye ekonomisinde kurumsal kalite göstergeleri ve ekonomik risk düzeyi ile doğrudan yabancı yatırımlar arasında olası uzun dönem etkileşimini ve nedensellik ilişkisini saptamayı amaçlayan bu çalışma, daha önce çok az sayıda çalışmanın kullandığı bir veri seti üzerinden ekonometrik analiz yapmakta ve konuyla ilgili Türkçe literatüre bu bağlamda katkı sağlamaktadır. Türkiye ekonomisi üzerinden bu konuyu inceleyen uygulamalı çalışmalarda kurumsal kalitenin ölçülmesi amacıyla çoğunlukla Dünya Bankası tarafından geliştirilen Dünya Yönetişim Göstergeleri (World Governance Indicators) ve Transparency International tarafindan geliştirilen yolsuzluk algı endeksinden (Corruption Perception Index) yararlanılmaktadır. Bu çalışmada ise International Country Risk Guide-ICRG veri kaynağından alınan kurumsal kalite göstergelerinden hareketle Temel Bileşenler Analizi tekniği ile kurumsal kalite endeksi oluşturulmuş ve doğrudan yabancı yatırım ile ilişkisi belirlenmeye çalışılmıştır. Çalışmada konuyla ilgili kısa bir bilgilendirmenin yapıldığı giriş bölümünü takiben ikinci bölümde kurumsal kalitenin ev sahibi ülkenin doğrudan yabancı yatırımları üzerinde nasıl etki yaratacağına dair teorik çerçeveye yer verilecektir. Konuyla ilgili literatür çalışmaları ve bulgularının derlendiği üçüncü bölümün ardından dördüncü bölümde ekonometrik yöntem, beşinci bölümde ise uygulamada yer alacak değişkenler ve veri seti tanıtılacaktır. Ekonometrik bulguların yorumlanacağ 1 altıncı bölümü takiben genel bir değerlendirme ve sonuç bölümüyle çalışma sonlandırılacaktır.

\section{Teorik Çerçeve}

Ekonomik gelişmişliği açıklamada kurumlara büyük rol atfeden ve kurumları "uzun dönemde ekonomik performansın altında yatan belirleyici unsur" (North, 1990: 107) olarak gören North (1990)'a göre "kurumlar, bir toplumda oyunun kuralları ya da daha resmi bir dille, insan etkileşimini düzenleyen ve yine insanlar tarafindan şekillendirilmiş sınırlamalar topluluğudur. Sonuç olarak, insanların siyasi, sosyal ya da ekonomik etkileşim insiyatiflerini oluştururlar.” (North, 1990: 3). Ekonomik performans üzerinde her ne kadar kültürel ve jeopolitik faktörlerin etkisi mevcut olsa da ülkeler arası büyüme farklılıklarının açıklanmasında en önemli faktör ekonomik kurumlardır. Ekonomik kurumlar, ekonominin yalnızca büyüme potansiyelini belirlemekle kalmaz aynı zamanda elde edilen çıktıların farklı gruplar ve bireyler arasında nasıl dağıtılacağını da belirlemeye yardımcı olurlar (Acemoğlu vd., 2005: 389-390).

Kurumsal kalite ve ekonomik gelişmişlik ilişkisine dair teorik literatür incelendiğinde kurumsal kalite düzeyi yüksek ülkelerin yatırım çekme kapasitesine özel bir vurgu yapılmaktadır. Bu doğrultuda özellikle gelişmekte olan ülkelerde ihtiyaç duyulan sermayenin ülkeye girişi yanında yeni teknolojilerin, pazarlama tekniklerinin ve yönetim bilgisinin de ev sahibi ülkeye taşınması, bilgi yayılması sürecini başlatacak ve yatırım yapılan ülkede verimliliğin ve rekabetçilik gücünün artırılmasına katkı sağlayacaktır (Javorcik, 2004: 605). Ancak doğrudan yabancı yatırımların sıralanan bu pozitif etkilerinin ortaya çıkabilmesi için hükümetlerin şeffaf, kapsamlı ve etkin kurumların bulunduğu ekonomik bir sistem hazırlaması ve ulusal politikaları bu doğrultuda hayata geçirmesi bir zorunluluktur (OECD, 2002: 3).

Ev sahibi ülkede kaliteli bir kurumsal yapının mevcudiyeti, verimlilik ve kar arayışında olan yabancı yatırımcının ülke tercihinde baktığı önemli bir kriterdir. Ayrıca ülke içinde yolsuzluk, rüşvet gibi uygulamaların yatırımlar üzerinde yaratacağ1 ek maliyetler, kurumsal kalitesi yüksek ülkeler için söz konusu olmayacaktır. Bununla birlikte düşük kurumsal kalitenin yaratacağı belirsizlik ortamı, yabancı yatırımcıların proje karar aşamasında dikkate alacağı temel faktörlerden bir diğeri olarak dikkat çekmektedir (Benassy-Quere vd., 2007: 764).

Doğrudan yabancı yatırım şeklinde ev sahibi ülkeye gelen çokuluslu şirketler, ev sahibi ülkede üretilen ürünlerin kalitesini artırmaya yönelik olarak teknik yardım ve eğitim desteği ile özellikle gelişmekte olan ülkelerde teknoloji transferi ve yayılımına yardımcı olmaktadırlar. Çokuluslu şirketler yardımıyla ülkeye gelen gelişmiş üretim tekniklerinin hammadde ve aramalı tedarik sürecinde de kullanılması geriye dönük bütünleşme sürecini başlatması yanında aynı endüstride faaliyet gösteren rakip veya tamamlayıcı şirketlerin yatay bütünleşmesine de imkan tanıyacaktır (OECD, 2002: 13)

Her ekonomide mülkiyet haklarını gözeten kurumsal bir yapının varlığı, fiziki ve beşeri sermaye yatırımlarını teşvik etmesi ve daha etkin teknolojilerin üretim sürecine uyarlanması yanında aynı zamanda kaynakların en etkin şekilde kullanılmak üzere tahsisini yaparak kazançların kesimler arası dağılımını da gerçekleştirirler. Bu doğrultuda faktör birikimini, yeniliği ve etkin kaynak dağılımını teşvik eden kurumlara sahip her ekonomide refah düzeyinin yükseleceği açıktır (Acemoğlu vd., 2005: 389).

Genel olarak kurumsal kalitenin pozitif ve anlamlı ekonomik kazanımlarının olacağı teorik açıdan yaygın kabul gören bir söylem olsa da yabancı yatırımcılar açısından bazı kalite göstergelerinin diğerlerine nazaran daha fazla öneme sahip olduğu belirtilebilir. Özellikle yasaların, kuralların ve politikaların öngörülemediği, aşırı düzenlemeye sahip, siyasi istikrardan uzak bir ekonomik sistemde doğrudan yabancı yatırımların bu koşullardan olumsuz etkileneceği açıktır (Daude ve Stein, 2007: 317).

\section{Literatür Taraması}

Kurumsal faktörlerin doğrudan yabancı yatırımlar üzerindeki etkisine dair yapılmış en eski çalışmalardan biri olan Wheler ve Mody (1992), ABD’nin çok uluslu şirketlerinin 1980'li yıllardaki imalat sanayi yatırımlarını konu edinmiştir. Toplamda 13 risk faktörü kullanılarak temel bileşenler analizi yardımıyla oluşturulan kurumsal kalite değişkeni ile 
ABD’nin yabancı ülkelerdeki şubelerinin lokasyonu arasındaki ilişkinin araştırıldığı bu çalışma sonucunda yüksek kurumsal kalitenin yabancı yatırımlar üzerinde önemli bir etkiye sahip olmadığı bulgusuna ulaşılmıştır.

Wei (1997), yolsuzluğun ülkede gelir ve servet dağılımında yol açtığı adaletsizlik yanında siyasi istikrarsızlığa yol açarak ülkeye doğrudan yabancı yatırım girişlerini olumsuz yönde etkileyeceğini belirtir. Benzer bir bulguya varan Habib ve Zurawicki (2002), yabancı yatırımcıların rüşvetin var olduğu ülkelere yatırım yapma konusunda çekingen davrandıklarını ayrıca yatırımcı ve ev sahibi ülkelerin yolsuzluk düzeyleri arasındaki farkın doğrudan yabancı yatırımlar için olumsuz bir faktör olduğuna dikkat çekmiştir. 12 ülkeden 45 ülkeye yapılan yatırımları dikkate alarak yolsuzluğun yabancı yatırımlar üzerine etkisini araştıran Wei (2000), ev sahibi ülkedeki yüksek vergi oranlarını ve rüşvetin yaygınlığını ülkeye giriş yapacak yabancı sermaye için olumsuz unsurlar olarak görmektedir. Daude ve Stain (2007) ise düşük kurumsal kalitenin yatırımlar üzerine yaratacağı belirsizlik yanında vergi yükü gibi bir maliyet oluşturacağından dolayı doğrudan yabancı yatırımları engelleyeceğine değinir.

Ülkeler arası kurumsal kalite düzeyi arasındaki farklılığın yabancı yatırımlar üzerine etkisini inceleyen bir diğer çalışmada Benassy-Quere vd. (2007), iyi kurumların ülkeye gelen yabancı sermaye miktarını çoğunlukla artırdığını ancak kurumsal kalite düzeyindeki farklılıkların karşılıklı yabancı yatırımlar üzerinde olumsuz etki yarattığına dikkat çekmektedir.

1972-2001 dönemi için 69 ülke üzerine çalışma yapan Busse (2004), demokratik hak ve özgürlüklerin geliştiği ülkelerde yabancı yatırım girişlerinin yüksek olacağına değinir. Stain ve Daude (2001), Kauffman vd. (1999) tarafından geliştirilen kurumsal kalite değişkenleri ile doğrudan yabancı yatırımlar arasında, ifade özgürlüğü ve hesap verilebilirlik dışında kalan diğer tüm kurumsal faktörler için güçlü ve pozitif yönlü bir ilişki olduğunu belirtir. Harms ve Ursprung (2002) ise 62 ülke için 1989-1997 dönemine ait verilere dayanarak doğrudan yabancı yatırımlar için bireysel özgürlüklerin ülkeye yabancı yatırım çekebilme adına önemli bir kriter olduğunun altını çizer. Smarzynska (1999), fikri mülkiyet haklarının doğrudan yabancı yatırımların hem miktar hem de bileşimini etkileyeceğine atıfta bulunarak, fikri mülkiyet haklarının iyi korunmadığı ülkelerde yabancı yatırımcıların özellikle teknoloji yoğun sektörlere yatırım yapma konusunda isteksiz olacaklarını söyler.

Globerman ve Shapiro (2002), 1995-1997 döneminde gelişmiş ve gelişmekte olan ülkelerden oluşan toplamda 114 örneklem için yönetişim altyapısının ülkeye gelen ve ülkeden çıkan doğrudan yabancı yatırımlar üzerine etkisini inceler. Globerman ve Shapiro (2002)'ya göre, yönetişim, yabancı yatırımcılar gözünde ev sahibi ülkenin cazibesini artırması yanında yerli çokuluslu firmaların yabancı ülkede yatırım yapabilmesi için uygun bir zeminin hazırlanmasına da yardımcı olur.

Kurumsal kalite göstergeleri içinde özellikle politik faktörlerin doğrudan yabancı yatırımlara etkisini konu edinen çalışmalardan Schneider ve Frey (1985), 80 az gelişmiş ülke üzerine yaptıkları çalışmaları neticesinde siyasi istikrarsızlığın yabancı yatırımcı için olumsuz bir faktör olduğuna dikkat çekerek siyasi kargaşanın hakim olduğu ülkelere karşı yabancı yatırımcıların isteksiz olacağını belirtir. Aynı doğrultuda yapılan bir diğer çalışmada Jun ve Singh (1996), siyasi istikrarın doğrudan yabancı yatırım üzerine olumlu etkisine dikkat çeker. Demokratik siyasi kurumlar ile ülkeye gelen yabancı yatırımlar arasında ilişki kuran Jensen (2003), 1970-1997 dönemi için yapmış olduğu analiz sonucu otoriter rejimlerden demokratik rejime geçişin doğrudan yabancı yatırımların GSYİH içindeki payını yaklaşık \%70 oranında artıracağından bahsetmektedir. Ülkenin daha demokratik bir yapıya sahip olmasını daha iyi bir yargı sisteminin tesis edilmesi ve hukuka güven duyulmasını sağlayacak bir unsur olarak gören ve yabancı yatırımcılar için iyi bir yatırım ortamının tesisine yardımcı olacağına değinen Li ve Resnick (2003), 1982-1995 dönemi için 53 gelişmekte olan ülke üzerine kurduğu model sonucunda mülkiyet haklarının korunduğu daha demokratik bir ekonomik yapının yabancı yatırımcılar üzerinde teşvik edici bir unsur olmadığını belirtir. 100 amerikan firmasının verilerini kullanarak fikri mülkiyet haklarının ABD’ye gelen doğrudan yabancı yatırımların bileşimi ve hacmi üzerindeki etkisini inceleyen Lee ve Mansfield (1996), değişkenler arası pozitif yönlü bir etkileşimin varlığına vurgu yapar. 83 gelişmekte olan ülke için 1984-2003 dönemine ait 12 farklı politik risk göstergesi kullanan Busse ve Hefeker (2005), iç çatışma ve etnik geriliminden uzak, temel demokratik hakların yasa ile korunduğu ve istikrarlı bir idari yapının var olduğu ülkelerde sıralanan bu kriterlerin ülkeye gelecek doğrudan yabancı yatırımların çok önemli bir belirleyicisi olduğuna işaret etmektedir. 2002-2010 dönemi için 8 ASEAN üyesi ülkede altı farklı kurumsal kalite bileşeninden hareketle(ifade özgürlüğü, siyasi istikrar, hukuka duyulan güven, mevzuat kalitesi, yolsuzluğun önlenmesi, hükümet etkinliği) elde ettiği ortalama kurumsal kalite göstergesinin doğrudan yabancı yatırımlara etkisini analiz eden Masron ve Nor (2013)'a göre kurumsal kalite, ülkeye gelen yabancı yatırımların önemli bir açıklayıcısıdır.

Türkiye ekonomisi özelinde yapılan çalışmalar incelendiğinde ise doğrudan yabancı yatırım girişi ile kurumsal faktörler arasındaki ilişkiye değinen çalışmaların çok az sayıda olduğu dikkat çekmektedir. Dumludağ (2009), Türkiye için yapılan çalışmalara dair literatür taraması sunmakta ve önceki çalışmalardan hiçbirinin kurumsal bakış açısı ile konuyu incelemediğinin altını çizmektedir. Dumludağ (2009)'a göre yapılan çalışmalar ya doğrudan yabancı yatırımların makro ve mikro ekonomik belirleyicilerine değinmekte ya da anket çalışması ile edindiği bulguları okuyucu ile paylaşmaktadır. Yaptığı çalışmada 2006 yılında Türkiye'de faaliyet gösteren 52 çokuluslu şirkete uyguladığı anket sonuçlarını da veren Dumludağ (2009); hükümet istikrarı, düşük seviyede yolsuzluk, şeffaf ve etkin bir yasal ve idari sistem, siyasi ve ekonomik istikrar, mülkiyet haklarının korunması gibi kurumsal faktörlerin yabancı yatırımları teşvik edeceğine vurgu yapmaktadır. Bu çalışmanın yanısıra Türkiye'nin de içinde yer aldığı 21 yükselen piyasa ekonomisinde konuyu inceleyen Dumludağ ve Şükrüoğlu (2007), etkin işleyen bir yargı sisteminin ve hükümet istikrarının mevcut olduğu, iç ve dış çatışmadan uzak ülkelerin yabancı yatırımcılar için cazip bir yatırım ortamı olacağına değinir. Kurumsal faktörlerin ülkemize gelecek yabancı yatırımcı için önemli olduğunu belirten diğer önemli çalışmalar Efe 
(2008) ve Demirtaş ve Akçay (2006)'a aittir. Efe (2008) bu önemli bulguya 1980-2006 dönemine ait veriler üzerinden, Demirtaş ve Akçay (2006) ise 1995-2002 dönemi için yaptığı analiz neticesinde ulaşmıştır.

\section{Ekonometrik Yöntem}

Granger ve Newbold (1974), zaman serisi analizlerinin ekonomik etkileşimi doğru şekilde ortaya koyabilmesi için modellerde yer alacak her bir serinin durağanlık sınamasına tabi tutulması gereğinden bahsetmektedir. Bu amaçla, Dickey ve Fuller (1981)'in teorik altyapısını şekillendirdiği ADF birim kök testi, değişkenlerin sabit terimsiz (Eşitlik 1) sabit terimli (Eşitlik 2) ve sabit terimli-trendli (Eşitlik 3) olma koşullarına göre üç adet model tahmin ederek durağanlık sınaması yapmaktadır. Bu yönteme göre tahmin edilecek modeller aşağıda ifade edilmiştir.

$$
\begin{aligned}
& \Delta Y_{t}=\delta Y_{t-1}+\sum_{i=1}^{m} \alpha_{i} \Delta Y_{t-i}+u_{t} \\
& \Delta Y_{t}=\beta_{1}+\delta Y_{t-1}+\sum_{i=1}^{m} \alpha_{i} \Delta Y_{t-i}+u_{t} \\
& \Delta Y_{t}=\beta_{1}+\beta_{2} t+\delta Y_{t-1}+\sum_{i=1}^{m} \alpha_{i} \Delta Y_{t-i}+u_{t}
\end{aligned}
$$

Eşitlik 1, 2 ve 3 'te $u_{t}$ hata terimini, $t$ trendi, $Y_{t-1}$ ise bağımlı değişkene ait bir dönem gecikmeli değeri göstermektedir. ADF testine göre serilerde birim kök olduğuna dair çıkarım yapılabilmesi için $\delta$ 'nın sıfıra eşit olması gerekmektedir. Yapılan test sonucunda $\delta$ 'ya ait elde edilen $t$ istatistiği, kritik MacKinnon tablo değerleri ile karşılaştırılmakta ve bu doğrultuda serilerin durağanlığına karar verilmektedir (Gujarati, 2004: 817). Serilerin durağan olması bir diğer ifadeyle birim kök içermemesi için MacKinnon kritik tablo değerinin elde edilen test istatistiğinden mutlak değerce daha büyük olması gerekmektedir.

ADF birim kök testi gibi, serilerde birim kökün varlığının araştırılması amacıyla Phillips ve Perron (1988) tarafindan, regresyon tahmini sonucu ulaşılan hata terimlerinin otokorelasyon ve değişen varyans sorunu taşımadığ 1 farklı bir metod geliştirilmiştir. Phillips-Perron birim kök testinde tahmin edilecek model ise Eşitlik 4'te ifade edilmiştir (Zivot ve Wang, 2006: 122-123).

$$
\Delta y_{t}=\beta^{\prime} D_{t}+\pi y_{t-1}+u_{t}
$$

Eşitlik 4'te yer alan $\Delta$, birinci fark işlemcisini, $Y_{t-1}$ bağımlı değişkene ait bir dönem gecikmeli değeri ve $u_{t}$ hata terimini ifade etmektedir. Bu yöntemde boş hipotez $Y_{t-1}$ 'nin katsayısı olan $\pi$ teriminin sıfıra eşit olması şeklinde kurulmuştur. Serinin birim kök içerip içermediğine yönelik çıkarım ise ADF testine benzer şekilde yapılmaktadır.

Değişkenler arasında uzun dönemli ilişkilerin varlığını tayin edebilmek amacıyla kullanılan Engle ve Granger (1987) ve Johansen $(1988,1991)$ eşbütünleşme yöntemleri, modelde yer alan değişkenlerin aynı düzeyde durağanlığını şart koşmakta, bu şartın geçerli olmadığı durumlarda bu yöntemlerden yararlanılamamaktadır. Farklı durağanlık mertebesine sahip olan değişkenlerde uzun dönem ilişkinin varlığı araştırılırken literatürde yaygın olarak sınır testi ve gecikmesi dağıtılmış otoregresif model (autoregressive distributed lag-ARDL) yönteminden faydalanılmaktadır.

Pesaran vd. (2001) tarafından geliştirilen sınır testinin ilk aşamasında modelde yer alacak değişkenlerin uzun dönemde ilişkili olup olmadığı araştırılmaktadır. Bu amaçla öncelikle Akaike (AIC) ve Schwarz (SBC) bilgi kriterlerinin önerdiği ve modellerde otokorelasyon sorunu yaratmayan uygun gecikme uzunluklarının tespiti büyük öneme sahiptir (Pesaran ve Shin, 1999: 373, 386). Sınır testi ile tahmin edilen modellerde uzun dönemli ilişkinin mevcut olduğuna yönelik bir çıkarım yapılırken regresyonlara ait F istatistiki değerleri ile Pesaran vd. (2001)'ın geliştirdiği kritik değerler mukayese edilir. Elde edilen F değerinin, Pesaran vd. (2001)'in üst sınır değerinden daha fazla olması, değişkenler arası uzun dönem ilişkisinin olduğu şeklinde yorumlanabilecektir (Pesaran vd., 2001: 290).

Sınır testi, değişkenler arası uzun dönemde ilişki olduğuna yönelik bir sonuca işaret ettiğinde ARDL yöntemi yardımıyla uzun ve kısa dönem katsayı tahminleri yapılabilecektir. Sınır testi yapılırken AIC ve SBC bilgi kriterlerinin işaret ettiği gecikme değerlerine göre hesaplanacak ARDL modeli Eşitlik 5'te, kısa dönemli katsayılarının elde edileceği hata düzeltme modeli (error correction model-ECM) ise Eşitlik 6'da sunulmuştur.

$$
\begin{aligned}
& Y_{t}=c_{0}+\sum_{i=1}^{p_{1}} \alpha_{i} Y_{t-i}+\sum_{i=0}^{q_{1}} \theta_{1 i} X_{t-i}+\sum_{i=0}^{q_{2}} \theta_{2 i} \pi_{t-i}+\sum_{i=0}^{q_{3}} \theta_{3 i} \partial_{t-i}+u_{t} \\
& \Delta Y_{t}=\mu+\sum_{i=1}^{p} \lambda_{i} \Delta Y_{t-i}+\sum_{i=0}^{p} \omega_{i} \Delta X_{t-i}+\sum_{i=0}^{p} \varphi_{i} \Delta \pi_{t-i}+\sum_{i=0}^{p} \gamma_{i} \Delta \partial_{t-i}+\vartheta E C M_{t-1}+u_{t}
\end{aligned}
$$

ECM modelinin ifade edildiği Eşitlik 6'da her bir parametrenin başındaki katsayılar değişkenlere ait kısa dönem katsayılarını verirken $\vartheta$ modelin hata düzeltme terimidir. Kısa dönem katsayı tahminlerinin güvenilirliği için $u_{t}$ hata terimlerinin ardışık bağımlılık ve değişen varyans sorunu taşımaması, normal dağılıma sahip olması gerekmektedir. Modellerde bu sorunların varlığı araştırılırken Breusch-Godfrey otokorelasyon testi, Jarque-Bera normal dağılım testi ve White değişen varyans testlerinden yararlanılmaktadır. Ayrıca ECM modelinde yer alan hata düzeltme katsayısının negatif işarete sahip olması ve istatistiki açıdan anlamlı çıkması, bu mekanizmanın iyi çalıştığının bir işaretidir.

\section{Veri Seti}


Türkiye ekonomisi için kurumsal kalite ve ekonomik risk düzeyinin doğrudan yabancı yatırım hacmi ve oynaklı̆̆1 üzerine etkisinin araştırıldığı bu çalışmada, 1998-2014 dönemine ait farklı veri kaynaklarından derlenen üçer aylık veriler kullanılarak sınır testi ve gecikmesi dağıtılmış otoregresif model (autoregressive distributed lag-ARDL) ile ekonometrik analiz yapılmıştır. Çalışmada kullanılan tüm değişkenler Merkez Bankası'ndan alınan ortalama kur değerleri kullanılarak TL'ye çevrilmiş ve logaritmik dönüşüm yapılarak analize dahil edilmiştir. Tablo 1'de ekonometrik analizde yer alacak değişkenlere ilişkin bilgiler sunulmaktadır.

Tablo 1. Ekonometrik Analizde Kullanılacak Değişkenler ve Veri Kaynakları

\begin{tabular}{|c|c|c|}
\hline Değişken & Tanım & Veri Kaynağı \\
\hline $\ln F D I$ & Doğrudan yabanc1 yatırım & $\begin{array}{l}\text { TCMB, Elektronik Veri Dağıtım } \\
\text { Sistemi }\end{array}$ \\
\hline $\ln I Q$ & Kurumsal kalite endeksi & $\begin{array}{l}\text { PRS Group ICRG verisetinden alınan } 9 \\
\text { farklı değişkenden hareketle Temel } \\
\text { Bileşenler Analizi ile oluşturulmuştur. }\end{array}$ \\
\hline $\ln R I S K$ & Ekonomik risk göstergesi & PRS Group ICRG veriseti \\
\hline $\ln I N V$ & Yurtiçi yatırım hacmi & TÜİK \\
\hline $\ln G D P P C$ & Kişi başı gelir düzeyi & $\begin{array}{l}\text { TCMB, Elektronik Veri Dağıtım } \\
\text { Sistemi }\end{array}$ \\
\hline $\operatorname{lnOPEN}$ & Dışa açıklık oranı & $\begin{array}{l}\text { TCMB, Elektronik Veri Dağıtım } \\
\text { Sistemi }\end{array}$ \\
\hline $\ln F D I_{V O L}$ & Doğrudan yabancı yatırım hacmindeki oynaklık & $\begin{array}{l}\text { TCMB, Elektronik Veri Dağıtım } \\
\text { Sistemi }\end{array}$ \\
\hline $\ln M S$ & Parasal büyüklüklerdeki değişim & $\begin{array}{l}\text { TCMB, Elektronik Veri Dağıtım } \\
\text { Sistemi }\end{array}$ \\
\hline
\end{tabular}

Kurumsal kalite ve ekonomik risk düzeyinin doğrudan yabancı yatırım hacmi üzerine etkisinin tespit edileceği ilk iki modelin bağımlı değişkeni $(F D I)$, Türkiye'ye giriş yapan doğrudan yabancı yatırım hacminin GSYİH içindeki payıdır. GSYİH ve doğrudan yabancı yatırım hacmine ait rakamlar, Merkez Bankası Elektronik Veri Dağıtım Sisteminden derlenmiştir. Kurumsal faktörlerin doğrudan yabancı yatırım oynaklığına etkisinin ölçüleceği üçüncü modelin bağımlı değişkeni ise doğrudan yabancı yatırımlardaki değişimdir $\left(F D I_{v O L}\right)$. Eşitlik 7, 8 ve 9'da tahmin edilecek uzun dönem denklemleri açıklanmaktadır.

$$
\begin{array}{lr}
\ln F D I=\beta_{0}+\beta_{1} \ln I Q+\beta_{2} \ln I N V+\beta_{3} \ln G D P P C+\beta_{4} \ln O P E N+\varepsilon & 7 \\
\ln F D I=\beta_{0}+\beta_{1} \ln R I S K+\beta_{2} \ln I N V+\beta_{3} \ln G D P P C+\beta_{4} \ln O P E N+\varepsilon & 8 \\
\ln F D I_{v O L}=\beta_{0}+\beta_{1} \ln I Q+\beta_{2} \ln M S+\beta_{3} \ln G D P P C+\beta_{4} \ln O P E N+\varepsilon & 9
\end{array}
$$

Kurumsal ve ekonomik göstergelerin doğrudan yabancı yatırım hacmi üzerine etkisinin araştırıldığı ilk modelde, International Country Risk Guide (ICRG) veri setinden derlenen 9 farklı kurumsal kalite göstergesinden hareketle Temel Bileşenler Analizi yardımıyla kurumsal kalite endeksi oluşturulmuştur. Kurumsal kalite endeksi (IQ), yolsuzluk (COR), demokratik hesap verilebilirlik (DA), iç ve dış çatışma (IC ve EXTC), hükümet istikrarı (GS), etnik gerginlik (ETHT), yatırım profili (IP), hukuka duyulan güven (LO) ve sosyoekonomik durum (SC) değişkenlerini kapsamaktadır. Çalışmanın ikinci kurumsal kalite göstergesi olan ekonomik risk değişkeni (RISK) de The PRS Group tarafından yayınlanan ICRG veri setinden derlenmiştir. Kullanılan kurumsal kalite değişkenlerine ait yüksek değerler düşük risk düzeyi ve yüksek kurumsal kalite anlamına geleceği için kurumsal kalite değişkeninin pozitif katsayıya sahip olacağı beklenmektedir.

Ayrıca tahmin edilecek modellerin güvenirliliğini artırmak amacıyla tüm modellere bazı kontrol değişkenleri dahil edilmiştir. Ülkedeki yaşam standardı ve ekonomik koşulları temsil etmesi amacıyla kişi başı GSYİH artışı (GDPPC), ve ülkenin dış dünya ile entegrasyon düzeyini ölçmesi için dışa açıklık düzeyi $(O P E N)$ (ithalat ve ihracat hacmi toplamının GSYİH içindeki payı), tüm modellere kontrol değişkenler olarak ilave edilmiştir. Bununla birlikte ev sahibi ülkedeki yatırım ortamının yabancı yatırımcılar için teşvik edici bir unsur olacağı düşüncesiyle ülkedeki sabit sermaye oluşumunu temsil etmesi için yurtiçi yatırımların GSYİH içindeki payı da (INV) modele eklenmiştir. Sıralanan tüm bu değişkenlere ait uzun dönem katsayılarının pozitif değer alacağı beklenmektedir. Kurumsal kalitenin(IQ), doğrudan yabancı yatırımların oynaklığı $\left(F D I_{v O L}\right)$ üzerine etkisini ölçmek amacıyla tahmin edilecek üçüncü modele kontrol değişken olarak para ve para benzerlerinin büyüme hızı $(M S)$ eklenmiştir. Para arzındaki artış, döviz kuru üzerinde belirsizlik yaratarak doğrudan yabancı yatırımları olumsuz etkileyeceği için bu değişken ile para politikasındaki çarpıklıklar temsil edilmeye çalışılmıştır. 


\section{Ampirik Bulgular}

Temel olarak kurumsal kalite göstergelerinin doğrudan yatırım hacmi üzerindeki etkisinin anlaşılmaya çalışıldığ bu çalışmada, ICRG tarafından yayınlanan 9 farklı kurumsal kalite göstergesi kullanılarak temel bileşenler analizi yardımıyla kurumsal kalite endeksi oluşturulmuştur. Temel bileşenler analizi neticesinde oluşturulan ve IQ olarak adlandırılan yeni kurumsal kalite endeksine ait özdeğer ve özvektör istatistikleri Tablo 2'de sunulmuştur.

Tablo 2. Kurumsal Kalite Endeksine Ait Özdeğer ve Özvektör İstatistikleri

\begin{tabular}{|c|c|c|c|c|c|c|}
\hline \multicolumn{7}{|c|}{ Özdeğerler(eigenvalues) } \\
\hline$C O R$ & $D A$ & ETHT & $I C-E X T C \quad G S$ & $I P$ & $L O$ & $S C$ \\
\hline 3.580074 & 1.444501 & 0.971385 & $\begin{array}{r}0.798570 \quad 0.454067 \\
\text { Oranlar (proportion }\end{array}$ & 0.419242 & 0.232844 & 0.099317 \\
\hline 0.4475 & 0.1806 & 0.1214 & $\begin{array}{cc}0.0998 & 0.0568 \\
\text { Özvektörler(eigenvec }^{2}\end{array}$ & 0.0524 & 0.0291 & 0.0124 \\
\hline 0.291 & 0.414 & -0.401 & -0.026 & -0.131 & 0.438 & 0.464 \\
\hline
\end{tabular}

Not: Tabloda yer alan kisaltmalarda COR-yolsuzluk, DA-demokratik hesap verilebilirlik , ETHT-etnik çatışma, IC-EXTC-iç ve dış çatışma, GS-hükümet istikrarı, IP-yatırım profili, LO-hukuka duyulan güven ve SC-sosyoekonomik durum değişkenlerini ifade etmektedir.

Temel bileşenler analizine göre ICRG veri setinden alınan dokuz göstergeden elde edilecek kurumsal kalite endeksine ait özdeğer, özvektör ve oran istatistikleri Tablo 2'de verilmiştir. Kullanılan dokuz bileşen, kurumsal kalite endeksindeki değişmenin tamamını açıklama gücüne sahiptir. Birinci bileşen olan yolsuzluk, kurumsal kalite endeksindeki değişmenin \%44'ünü, demokratik hesap verilebilirlik bileşeni \%18'ini, etnik çatışma \%12'sini açıklayabilmektedir. Özvektör istatistikleri ise kurumsal kalite endeksi hesaplanırken her bir göstergenin alacağı katsayıyı göstermektedir.

Kurumsal kalite ve ekonomik risk göstergeleri ile Türkiye’ye gelen doğrudan yabancı yatırım hacmi arasındaki ilişkiyi tespit etmek amacıyla tahmin edilecek üç modelde yer alan değişkenlere ait birim kök sınamaları Dickey ve Fuller (1981) ADF birim kök testi ve Phillips ve Perron (1988) PP birim kök testi yardımıyla yapılmıştır. Elde edilen durağanlık test sonuçları Tablo 3 'te sunulmuştur.

Tablo 3. Serilere Ait ADF ve PP Birim Kök Testi Sonuçları

\begin{tabular}{|c|c|c|c|c|}
\hline & \multicolumn{2}{|c|}{ Orjinal Seriler } & \multicolumn{2}{|c|}{ Birinci Farkı Alınan Seriler } \\
\hline & $A D F$ & $\boldsymbol{P P}$ & $A D F$ & $P P$ \\
\hline & -0.808 & $-4.519 * * *$ & $-8.955 * * *$ & $-13.91 * * *$ \\
\hline $\ln F D I$ & $(0.95)$ & $(0.00)$ & $(0.00)$ & $(0.00)$ \\
\hline $\ln I Q$ & $\begin{array}{l}-0.464 \\
(0.98)\end{array}$ & $\begin{array}{l}-0.375 \\
(0.98)\end{array}$ & $\begin{array}{c}-6.068 * * * \\
(0.00)\end{array}$ & $\begin{array}{c}-6.068 * * * \\
(0.00)\end{array}$ \\
\hline $\ln R I S K$ & $\begin{array}{c}-3.832 * * \\
(0.02)\end{array}$ & $\begin{array}{c}-3.563 * * \\
(0.04)\end{array}$ & $\begin{array}{c}-7.739 * * * \\
(0.00)\end{array}$ & $\begin{array}{c}-12.71 * * * \\
(0.00)\end{array}$ \\
\hline $\ln I N V$ & $\begin{array}{l}-2.303 \\
(0.42)\end{array}$ & $\begin{array}{c}-3.173 * \\
(0.10)\end{array}$ & $\begin{array}{c}-2.927 * * \\
(0.05)\end{array}$ & $\begin{array}{c}-11.11 * * * \\
(0.00)\end{array}$ \\
\hline $\ln G D P P C$ & $\begin{array}{l}-0.663 \\
(0.96)\end{array}$ & $\begin{array}{c}-4.615 * * * \\
(0.00)\end{array}$ & $\begin{array}{c}-4.936 * * * \\
(0.00)\end{array}$ & $\begin{array}{c}-11.82 * * * \\
(0.00)\end{array}$ \\
\hline $\operatorname{lnOPEN}$ & $\begin{array}{l}-0.858 \\
(0.95)\end{array}$ & $\begin{array}{c}-3.994 * * \\
(0.01)\end{array}$ & $\begin{array}{c}-7.771 * * * \\
(0.00)\end{array}$ & $\begin{array}{c}-18.62 * * * \\
(0.00)\end{array}$ \\
\hline $\ln F D I_{V O L}$ & $\begin{array}{c}-8.955 * * * \\
(0.00)\end{array}$ & $\begin{array}{c}-13.91 * * * \\
(0.00)\end{array}$ & $\begin{array}{c}-9.788 * * * \\
(0.00)\end{array}$ & $\begin{array}{c}-19.45 * * * \\
(0.00)\end{array}$ \\
\hline $\ln M S$ & $\begin{array}{r}-2.062 \\
(0.55)\end{array}$ & $\begin{array}{l}-2.127 \\
(0.51)\end{array}$ & $\begin{array}{c}-3.506 * * \\
(0.01)\end{array}$ & $\begin{array}{c}-3.312 * * \\
(0.01)\end{array}$ \\
\hline \multicolumn{3}{|c|}{ Kritik Değerler } & \multicolumn{2}{|c|}{ Kritik Dĕgerler } \\
\hline $1 \%$ & -4.165 & -4.156 & -3.577 & -3.574 \\
\hline $5 \%$ & -3.508 & -3.504 & -2.925 & -2.923 \\
\hline $10 \%$ & -3.184 & -3.181 & -2.600 & -2.599 \\
\hline
\end{tabular}

Not: Parantez içinde yer alan rakamlar olasılı değerini; ${ }^{* * *},{ }^{* *},{ }^{*}$ ise sırasıyla \%1, 5 ve 10 önem düzeyinde anlamlılı̆̆ ifade etmektedir. 
Modellerde yer alan değişkenlere ait Phillips-Perron durağanlık sınaması bulgularına göre, doğrudan yabancı yatırım $(F D I)$, kişi başı gelir $(G D P P C)$ ve yabancı yatırım oynaklığı $\left(F D I_{V O L}\right)$ değişkenlerinin \%1; ekonomik risk $(R I S K)$ ve dışa açıklık $(O P E N)$ değişkeninin \%5, yurtiçi yatırım değişkeninin (INV) ise \%10 anlamlılık seviyesinde durağanlaştığı teknik bir ifadeyle sıralanan serilerin I(0) çıktığı gözlenmektedir. Orijinal serilere uygulanan ADF birim kök test sonuçları ise ekonomik risk $(R I S K)$ ve yabancı yatırım oynaklığı $\left(F D I_{V O L}\right)$ değişkenleri dışında kalan diğer tüm değişkenler için anlamsız çıkmıştır. Birinci farkları alınarak yeniden birim kök sınamasına tabi tutulan serilerden doğrudan yabancı yatırımlar $(F D I)$, kurumsal kalite $(I Q)$, kişi başı gelir düzeyi (GDPPC), ekonomik risk (RISK) ve dışa açıklık $(O P E N)$ değişkenleri hem ADF hem de PP testine göre \%1 önem düzeyinde durağan çıkmıştır. Ayrıca para arzı $(M S)$ değişkeninin birinci farkı ADF ve PP testine göre \%5 önem düzeyinde, yurtiçi yatırım değişkeninin $(I N V)$ birinci farkı ise $\mathrm{ADF}$ testine göre \%5, PP testine göre \%1 önem düzeyinde durağanlaşmıştır.

Yapılan birim kök test sonuçlarına bakıldığında serilerin farklı düzeyde durağanlığa sahip olduğu belirlenmiştir. Bu doğrultuda farklı düzeyde durağanlığa sahip seriler arasında uzun dönemli ilişkinin tespiti amacıyla geliştirilen sınır testi ve ARDL metodu ile analize devam edilerek öncelikle uzun dönemli ilişkinin varlığı araştırılmış sonrasında ise uzun dönem katsayılar elde edilmiştir. Uzun dönem katsayılara ulaşmak amacıyla tahmin edilecek denklemler, Model 1,2 ve 3 olarak aşağıda sunulmuştur.

$$
\begin{aligned}
& \ln F D I=\beta_{0}+\beta_{1} \ln I Q+\beta_{2} \ln I N V+\beta_{3} \ln G D P P C+\beta_{4} \ln O P E N+\varepsilon \\
& \ln F D I=\beta_{0}+\beta_{1} \ln R I S K+\beta_{2} \ln I N V+\beta_{3} \ln G D P P C+\beta_{4} \ln O P E N+\varepsilon \\
& \ln F D I_{v O L}=\beta_{0}+\beta_{1} \ln I Q+\beta_{2} \ln M S+\beta_{3} \ln G D P P C+\beta_{4} \ln O P E N+\varepsilon
\end{aligned}
$$

Model 1

Model 2

\begin{tabular}{|c|c|c|c|c|c|c|c|c|}
\hline & \multicolumn{4}{|c|}{ Sabit Terimli Model } & \multicolumn{4}{|c|}{ Sabit Terimli ve Trendli Model } \\
\hline & $p$ & $A I C$ & $\chi^{2}(1)$ & $\chi^{2}(4)$ & $p$ & $A I C$ & $\chi^{2}(1)$ & $\chi^{2}(4)$ \\
\hline Model 1 & 1 & 2.022 & $\begin{array}{l}2.486 \\
(0.11)\end{array}$ & $\begin{array}{l}7.341 \\
(0.11)\end{array}$ & 1 & 2.063 & $\begin{array}{l}2.745 \\
(0.09)\end{array}$ & $\begin{array}{l}7.777 \\
(0.10)\end{array}$ \\
\hline Model 2 & 1 & 2.070 & $\begin{array}{l}2.226 \\
(0.13)\end{array}$ & $\begin{array}{l}10.37 \\
(0.03)\end{array}$ & 1 & 2.092 & $\begin{array}{l}1.977 \\
(0.15)\end{array}$ & $\begin{array}{l}9.969 \\
(0.04)\end{array}$ \\
\hline \multirow[t]{3}{*}{ Model 3} & 1 & 2.032 & $\begin{array}{l}1.313 \\
(0.25)\end{array}$ & $\begin{array}{l}4.382 \\
(0.35)\end{array}$ & 1 & 1.864 & $\begin{array}{l}8.926 \\
(0.06)\end{array}$ & $\begin{array}{l}2.789 \\
(0.09)\end{array}$ \\
\hline & \multicolumn{4}{|c|}{ Sabit Terimli Model } & \multicolumn{4}{|c|}{ Sabit Terimli ve Trendli Model } \\
\hline & $p$ & $S B C$ & $\chi^{2}(1)$ & $\chi^{2}(4)$ & $p$ & $S B C$ & $\chi^{2}(1)$ & $\chi^{2}(4)$ \\
\hline Model 1 & 1 & 2.408 & $\begin{array}{l}2.486 \\
(0.11)\end{array}$ & $\begin{array}{l}7.341 \\
(0.11)\end{array}$ & 1 & 2.487 & $\begin{array}{l}2.745 \\
(0.09)\end{array}$ & $\begin{array}{l}7.777 \\
(0.10)\end{array}$ \\
\hline Model 2 & 1 & 2.456 & $\begin{array}{l}2.486 \\
(0.11)\end{array}$ & $\begin{array}{l}7.341 \\
(0.11)\end{array}$ & 1 & 2.516 & $\begin{array}{l}1.977 \\
(0.15)\end{array}$ & $\begin{array}{l}9.969 \\
(0.04)\end{array}$ \\
\hline Model 3 & 1 & 2.495 & $\begin{array}{l}1.313 \\
(0.25)\end{array}$ & $\begin{array}{l}4.382 \\
(0.35)\end{array}$ & 1 & 2.366 & $\begin{array}{l}8.926 \\
(0.06)\end{array}$ & $\begin{array}{l}2.789 \\
(0.09)\end{array}$ \\
\hline
\end{tabular}

Model 3

Tablo 4. Akaike ve Schwarz Bilgi Kriterlerinin Önerdiği Gecikme Uzunlukları

Not: $p$ değeri AIC ve SBC bilgi kriterleri tarafindan önerilen uygun gecikme uzunluğınu temsil etmektedir. $\chi^{2}(1)$ ve $\chi^{2}(4)$ ise serilerin 1. ve 4. birinci ve dördüncü gecikmelerine ait ardlşık bağımlılık LM test sonuçlarını göstermektedir. Parantez içinde yer alan rakamlar ise LM test istatistiğinin olasılık de ğeridir.

Sınır testi ile değişkenler arası uzun dönemli ilişkinin varlığı araştırılırken modellerin tahmininde kullanılacak gecikme uzunluklarının tespiti önemli bir aşamayı oluşturmaktadır. Zira bu gecikme uzunlukları kullanılarak tahmin edilen modellerin ardışık bağımlılık sorunu taşımaması gerekmektedir. Tablo 4 'te Akaike ve Schwarz bilgi kriterlerinin uygun gördüğü gecikme uzunlukları ve modellerin 1. ve 4. gecikmelerine ait LM ardışık bağımlılık test sonuçları sunulmuştur. Bu sonuçlara göre tahmin edilen 3 modelin sabitli ve sabitli-trendli versiyonlarında Akaike ve Schwarz kriterlerine göre önerilen gecikme uzunluğu 1'dir. 1 olarak önerilen gecikme uzunluğuyla kurulmuş tüm modellerin sabitli ve sabitli-trendli versiyonlarının hiçbiri, 1. gecikmede ardışık bağımlılık sorunu taşımamaktadır. Ancak ekonomik risk ve doğrudan yabanc1 yatırım modelinin hem sabitli hem de sabitli-trendli versiyonu, 4 . gecikmede $\% 5$ düzeyinde ardışık bağımlılık sorunu taşırken, \%1 düzeyinde bu sorun ortadan kalmaktadır. Bundan sonraki aşamalarda modeller tahmin edilirken Akaike ve Schwarz kriterleri tarafından önerilen ortak gecikme uzunluğu olarak 1 esas alınmış ve sınır testine geçilmiştir. 
Ozsahin, S. / Journal of Yasar University, 2016, 11/44, 251-262

Tablo 5. Tahmin Edilen Modellere İlişkin Sınır Testi Sonuçları

\begin{tabular}{lccccccc}
\hline & \multicolumn{4}{c}{ Trendli Model } & \multicolumn{3}{c}{ Trendsiz Model } \\
\cline { 2 - 8 } & $p$ & $F-i v$ & $F-v$ & $t-v$ & $p$ & $F-i i i$ & $t$-iii \\
Model 1 & 1 & $6.347^{*}$ & $7.149^{*}$ & $-5.612^{*}$ & 1 & $7.813^{*}$ & $-5.932^{*}$ \\
Model 2 & 1 & $7.127^{*}$ & $8.401^{*}$ & $-6.081^{*}$ & 1 & $8.466^{*}$ & $-6.084^{*}$ \\
Model 3 & 1 & $6.906^{*}$ & $7.737^{*}$ & $-5.854^{*}$ & 1 & $6.664^{*}$ & $-5.176^{*}$ \\
\hline
\end{tabular}

Not: ${ }^{*}$ modelin tahmini sonucunda ulaşllan değerin Pesaran vd.(2001)'in \%5 düzeyine ait üst sinır de ğerinden daha fazla olduğu göstermektedir.

Sınır testi sonuçlarına göre tahmin edilen üç modele ait F-iii, F-iv, F-v, t-iii ve t-v istatistikleri Tablo 5'te sunulmuştur. Her üç modelin trendli ve trendsiz versiyonlarına ait istatistikler Pesaran vd. (2001)'in \%5 anlam düzeyindeki kritik üst değerinden daha yüksek çıktığı için tahmin edilen regresyonlarda uzun dönemli ilişki olmadığını belirten boş hipotez reddedilerek alternatif hipotez kabul edilmektedir. Bu bulguya göre tahmin edilen her üç model için seviye ilişkisinin bulunduğu yorumu yapılabilecektir. Bu bilgiye dayanarak bir sonraki aşamada 1 olarak belirlenen uygun gecikme uzunluğuyla parametrelere ait uzun dönemli katsayı tahminleri yapılmıştır. Tablo 6'da Model 1, 2 ve 3'e ait uzun dönem katsayı tahminleri modellerin sabitli ve trendli versiyonlara göre farklılık gösterebileceği hususu dikkate alınarak ayrıntılı şekilde sunulmaktadır.

Tablo 6. Uzun Dönem Parametre Katsayı Tahmin Sonuçları

\begin{tabular}{|c|c|c|c|c|c|c|}
\hline & \multicolumn{6}{|c|}{ Sabitli Model } \\
\hline & $\ln I Q$ & $\ln R I S K$ & $\ln I N V$ & $\ln G D P P C$ & $\operatorname{lnOPEN}$ & $\ln M S$ \\
\hline Model 1 & $\begin{array}{l}2.823 * \\
(-1.68)\end{array}$ & & $\begin{array}{c}4.447 * * * \\
(5.16)\end{array}$ & $\begin{array}{c}1.669 * * * \\
(5.409)\end{array}$ & $\begin{array}{c}3.120 * * * \\
(2.702)\end{array}$ & \\
\hline Model 2 & & $\begin{array}{c}0.434 \\
(0.435)\end{array}$ & $\begin{array}{c}4.215 * * * \\
(3.78)\end{array}$ & $\begin{array}{c}1.420 * * * \\
(4.638)\end{array}$ & $\begin{array}{c}2.576 * * \\
(2.130)\end{array}$ & \\
\hline \multirow[t]{3}{*}{ Model 3} & $\begin{array}{l}-3.86 * * \\
(2.219)\end{array}$ & & & $\begin{array}{l}-1.069^{*} \\
(-1.637) \\
\end{array}$ & $\begin{array}{l}1.663^{*} \\
(1.619)\end{array}$ & $\begin{array}{c}1.21 * * * \\
(3.958)\end{array}$ \\
\hline & \multicolumn{6}{|c|}{ Trendli Model } \\
\hline & $\ln I Q$ & $\ln R I S K$ & $\ln I N V$ & $\ln G D P P C$ & $\operatorname{lnOPEN}$ & $\ln M S$ \\
\hline Model 1 & $\begin{array}{c}3.408 * \\
(-1.490)\end{array}$ & & $\begin{array}{c}4.676^{* * * *} \\
(4.420)\end{array}$ & $\begin{array}{c}1.979 * * \\
(2.269)\end{array}$ & $\begin{array}{c}3.031 * * \\
(2.545)\end{array}$ & \\
\hline Model 2 & & $\begin{array}{c}1.127 * \\
(-0.984)\end{array}$ & $\begin{array}{c}4.428 * * * \\
(3.948)\end{array}$ & $\begin{array}{l}0.877^{*} \\
(1.617)\end{array}$ & $\begin{array}{c}2.833 * * \\
(2.320)\end{array}$ & \\
\hline Model 3 & $\begin{array}{l}-2.199 * \\
(1.220)\end{array}$ & & & $\begin{array}{l}-0.715^{*} \\
(-1.117)\end{array}$ & $\begin{array}{c}0.986 * \\
(0.966)\end{array}$ & $\begin{array}{c}2.498 * * * \\
(4.023)\end{array}$ \\
\hline
\end{tabular}

Not: Parantez içinde yer alan rakamlar t-istatistiğini vermektedir.

***, **, * siraslyla \%1, 5 ve 10 önem düzeyinde anlamlılı̆̆ ifade etmektedir.

Kurumsal kalitenin doğrudan yabancı yatırımlar üzerindeki etkisini incelediğimiz ilk modelin uzun dönem katsayı tahmin sonuçlarına baktığımızda, Türkiye üzerine yapılmış Dumludağ (2009), Dumludağ ve Şükrüoğlu (2007), Demirtaş ve Akçay (2006) ve Efe (2008) çalışmalarını destekler şekilde, kurumsal kalite endeksinin pozitif işaretli ve \%1 önem düzeyinde anlamlı bir değişken olduğu görülmektedir. Bu bulgu, ülke içinde kurumsal kalitedeki artışın bilgi asimetrilerini azaltması ve daha iyi bir yatırım ortamının tesis edilmesine yardımcı olmasından ötürü ülkenin yabancı yatırımları çekme gücünü artıracağı şeklinde yorumlanabilir. Yurtiçi yatırım değişkeninin yine pozitif işaretli ve anlamlı bir değişken olması, yurtiçi yatırımlardaki artışın yabancılar tarafından ülke içinde uygun bir yatırım iklimi olduğu şeklinde algılanacağı anlamına gelmektedir. Kişi başı gelir düzeyindeki artış da tıpkı dışa açıklık değişkeni gibi pozitif işaretli ve anlamlı bir değişkendir. Bu bulgular Türkiye'de yaşam kalitesinin yükselmesi ve dış dünya ile entegrasyonun doğrudan yabancı yatırımları olumlu yönde etkilediğini doğrulamaktadır. Ekonomik risk düzeyinin yabancı yatırımlar üzerine etkisini ölçmeye çalıştığımız ikinci model sonucunda, düşük ekonomik risk düzeyi, dış dünya ile yoğun entegrasyon, yurtiçi yatırımların yüksekliği ve kişi başı gelir artışının Türkiye’nin yabancı yatırım çekme kapasitesini artıran faktörler olduğu görülmüştür.

Doğrudan yabancı yatırımların oynaklığını bağımlı değişken olarak aldığımız üçüncü modelin uzun dönem katsayı tahmin sonuçları incelendiğinde ise kurumsal kalite endeksinin negatif işaretli ve \%10 seviyesinde istatistiksel olarak 
anlamlı sonuç verdiği görülmektedir. Bu bulgu, Türkiye'de kurumsal kalite düzeyindeki artışın doğrudan yabanc1 yatırımların oynaklığını azaltacağı şeklinde yorumlanabilecektir. Ayrıca para arzındaki artış, Türkiye'ye gelen doğrudan yabancı yatırımlardaki oynaklığı pozitif yönde ve \%1 önem düzeyinde anlamlı olarak etkileyen bir diğer değişkendir. Kişi başı gelir artışının negatif işaretli ve istatistiksel olarak anlamlı çıkması, Türkiye'de ekonomik büyümenin doğrudan yabancı yatırım oynaklığını azalttığına işaret etmektedir.

Ulaşılan uzun dönem katsayıları Türkiye ekonomisi üzerine yapılan az sayıdaki geçmiş çalışmalarla mukayese edildiğinde benzer bulgulara işeret ettiği söylenebilecektir. Örneğin Dumludağ ve Şükrüoğlu (2007), Demirtaş ve Akçay (2006)'a göre dışa açıklık oranı doğrudan yabancı yatırımları artırıcı etkilere sahiptir. Ancak bu çalışmada kişi başı gelir düzeyindeki artışın yabancı yatırımlar üzerindeki etkisi Dumludağ ve Şükrüoğlu (2007) gibi pozitif yönlü olsa da Demirtaş ve Akçay (2006)'a göre bu etki belirsizdir.

Uzun dönem katsayılarının elde edilmesinin ardından bir sonraki aşamada Eşitlik 6'da ifade edilen denklem aracılığıyla vektör hata düzeltme modeli tahmin edilmiş ve nedensellik ilişkileri belirlenmeye çalışılmıştır. Nedensellik ilişkilerini belirlemek üzere yapılan Granger nedensellik testi bulguları Tablo 7'de sunulmuştur.

Tablo 7. Granger Nedensellik Testi Sonuçları

\begin{tabular}{ll}
\hline & Nedenselliğin Yönü \\
\hline \multirow{2}{*}{ Model 1 } & IQ $\Leftrightarrow$ OPEN \\
& IQ $\rightarrow$ FDI \\
& FDI $\rightarrow$ OPEN \\
\hline \multirow{2}{*}{ Model 2 } & RISK $\rightarrow$ INV \\
& INV $\rightarrow$ FDI \\
& FDI $\rightarrow$ OPEN \\
\hline Model 3 & MS $\Leftrightarrow$ FDI Oynaklı̆̆ \\
\hline
\end{tabular}

Tablo 7'de yer alan Granger nedensellik testi sonuçlarına göre kurumsal kalite düzeyinden doğrudan yabancı yatırım girişine doğru tek yönlü nedensellik ilişkisi, kurumsal kalite ve dışa açıklık değişkenleri arasında ise çift yönlü nedensellik ilişkisinin bulunduğu tespit edilmiştir. Ekonomik risk modeli çerçevesinde ise ekonomik risk düzeyi yurtiçi yatırımların nedeni, yurtiçi yatırımlar ise doğrudan yabancı yatırımların nedeni olarak belirlenmiştir. Tahmin edilen her iki modelde doğrudan yabancı yatırımlardan dışa açıklığa doğru tek yönlü bir nedensellik bulgulanmıştır. Doğrudan yabancı yatırım oynaklığı ile para arzındaki artış arasında da çift yönlü bir nedensellik ilişkisi saptanmıştır.

\section{Sonuç}

Kurumsal kalite açısından belli bir eşiğin ötesindeki gelişmekte olan ülkelerin, yabancı yatırımcıları ülkeye çekmesi neticesinde ileri teknoloji ve yönetim bilgisine adaptasyon gibi önemli kazanımlar sağlayacağı konusunda literatürde genel bir kabul mevcuttur. Türkiye'de kurumsal kalite ve ekonomik risk düzeyinin doğrudan yabancı yatırım hacmi ve oynaklığı üzerinde sahip olduğu etkiyi teorik ve ekonometrik açıdan ortaya koymayı amaçlayan bu çalışmada, Türkiye üzerine yapılan az sayıdaki çalışmadan farklı olarak üç farklı model tahmin edilmiştir. Kurumsal kalite düzeyinin doğrudan yabancı yatırım hacmi üzerindeki etkisinin tespitine yönelik tahmin edilen ilk modelde, ICRG tarafından yayınlanan dokuz farklı kurumsal kalite göstergesi kullanılarak Türkiye için kurumsal kalite endeksi oluşturulmuştur. Yolsuzluk, demokratik hesap verilebilirlik, iç ve dış çatışma, hükümet istikrarı, etnik gerginlik, yatırım profili, hukuka duyulan güven ve sosyoekonomik durum değişkenlerini içeren kurumsal kalite endeksine göre yüksek kurumsal kalite, Türkiye'ye gelecek doğrudan yabancı yatırımlar üzerinde pozitif yönlü, istatistiksel olarak anlamlı etkiye sahiptir. Bunun yanı sıra ekonomik riskin doğrudan yabancı yatırım hacmi üzerindeki etkisinin araştırıldığı modele göre ise düşük ekonomik risk, doğrudan yabancı yatırımlar için pozitif yönlü anlamlı etkiye sahip bir değişkendir.

Ayrıca tahmin edilen modellerin daha güvenilir sonuçlar verebilmesi amacıyla yurtiçi yatırımın GSYİH içindeki payı, dışa açıklık oranı, kişi başı GSYİH artışı kontrol değişkenler olarak modellere dahil edilmiştir. Sınır testi ve ARDL yöntemi yardımıyla elde edilen bulgulara göre sıralanan tüm değişkenlerin doğrudan yabancı yatırımlar üzerinde pozitif yönlü ve istatistiksel olarak anlamlı etkilere sahip olduğu gözlenmiştir. Doğrudan yabancı yatırım oynaklığının belirleyicileri üzerine kurulan bir diğer modele göre ise kurumsal kalitedeki artış doğrudan yabancı yatırım oynaklığını azaltıcı, para arzındaki artış hızı ise doğrudan yabancı yatırım oynaklı̆̆ını artırıcı etkilere sahiptir. 


\section{KAYNAKÇA}

Acemoğlu, Daron, Johnson, Simon ve Robinson, James A. (2005), “Institutions as a Fundamental Cause of Long-Run Growth" Handbook of Economic Growth, (edt.) Philippe Aghion ve Stephen Durlauf, Elsevier, Amsterdam, ss.386-469.

Aghion, Phillippe ve Peter Howitt (1992), “A Model of Growth through Creative Destruction”, Econometrica, Vol.60, No.2, ss.323-351.

Benassy-Quere, Agnes, Coupet, Maylis ve Mayer, Thierry (2007), "Institutional Determinants of Foreign Direct Investment", The World Economy, Vol.30, No.5, ss. 764-782.

Busse, Matthias ve Hefeker, Carsten (2005), Political Risk, Institutions and Foreign Direct Investment, HWWA Discussion Paper, Paper No.315.

Busse, Matthias (2004), "Transnational Corporations and Repression of Political Rights and Civil Liberties: An Empirical Analysis", Kyklos, Vol. 57, No. 1, ss. 45-66.

Daude, Christian ve Stein, Ernesto (2007), “The Quality of Institutions and Foreign Direct Investment”, Economics and Politics, Vol.19, No.3, ss. 317-344.

Demirtaş, Gökhan ve Akçay, Selçuk (2006), "Kurumsal Faktörlerin Doğrudan Yabancı Yatırımlar Üzerine Etkisi: Ampirik Bir Kanıt”, Gazi Üniversitesi İIBF Dergisi, Vol. 8, No. 2, ss. 15-34.

Dickey, David A. ve Fuller, Wayne A. (1981), "Likelihood Ratio Tests for Autoregressive Time Series with a Unit Root", Econometrica,Vol. 49, ss.1057-1072.

Dumludağ, Devrim ve Şükrüoğlu, Deniz (2007), “The Impact of Macroeconomic and Institutional Variables on Foreign Direct Investment Flows in Emerging Markets”, Marmara Üniversitesi İïB Dergisi, Vol. 23, No. 2), ss. 133166.

Dumludağ, Devrim (2009), “An Analysis of the Determinants of Foreign Direct Investment in Turkey: The Role of the Institutional Context”, Journal of Business Economics and Management, Vol. 10, No. 1, ss: 15-30.

Efe, Gürkan (2008). Uluslararası Sermaye Hareketleri, Kurumsal Kalite ve Ekonomik Büyüme, Atatürk Üniversitesi Sosyal Bilimler Enstitüsü Yayınlanmamış Yüksek Lisans Tezi, Erzurum.

Engle, Robert F. ve Granger, Clive W.J. (1987), "Co-integration and Error Correction: Representation, Estimation and Testing”, Econometrica, Vol.55, No.2, ss. 251-276.

Globerman, S. and D. Shapiro (2002), "Global Foreign Direct Investment Flows: The Role of Governance Infrastructure", World Development, Vol.30, No.11, ss. 1899-1919.

Granger, Clive W. ve Newbold, Paul (1974), "Spurious Regressions in Econometrics”, Journal of Econometrics, Vol. 2, No. 2, ss. 111-120.

Grossman, Gene ve Helpman, Elhanan (1991), Innovation and Growth in the Global Economy, MIT Press, Cambridge.

Gujarati, Damodar (2004), Temel Ekonometri, Literatür Yayıncılık: İstanbul.

Habib, Mohsin ve Zurawicki, Leon (2002), "Corruption and Foreign Direct Investment", Journal of International Business Studies, Vol.33, No.2, ss. 297-307.

Hall, Robert E. ve Jones, Charles I. (1999), “Why Do Some Countries Produce So Much More Output Per Worker Than Others?", The Quarterly Journal of Economics, Vol. 114, No.1, ss. 83-116.

Harms, Philipp ve Ursprung, Heinrich W. (2002), "Do Civil and Political Repression Really Boost Foreign Direct Investments?", Economic Inquiry, Vol.40, No.4, ss. 651-663.

Javorcik, Beata S. (2004), "Does Foreign Direct Investment Increase the Productivity of Domestic Firms? In Search of Spillovers through Backward Linkages", American Economic Review, Vol.94, No.3, ss. 605-627.

Jensen, Nathan (2003), "Democratic Governance and Multinational Corporations: Political Regimes and Inflows of Foreign Direct Investment", International Organization, Vol.57, No.3, ss. 587-616.

Johansen, Soren (1988), "Statistical Analysis of Cointegration Vectors," Journal of Economic Dynamics and Control, Vol. 12, No. 2-3, ss. 231-254.

Johansen, Soren (1991), "Estimation and Hypothesis Testing of Cointegration Vectors in Gaussian Vector Autoregressive Models," Econometrica, Vol. 59, No. 6, ss. 1551-1580.

Jun, Kwang ve Harinder Singh (1996), "The Determinants of Foreign Direct Investment in Developing Countries", Transnational Corporations, Vol. 5, No. 2, ss. 67-105.

Kaufmann, Daniel, Kraay, Aart ve Zoido-Lobaton, Pablo (1999), “Governance Matters”, Policy Research Working Paper Series 2196, The World Bank.

Lee, Jeong-Yeon ve Mansfield, Edwin (1996), "Intellectual Property Protection and U.S. Foreign Direct Investment", The Review of Economics and Statistics, Vol.78, ss.181-186.

Li, Quan ve Resnick, Adam (2003), "Reversal of Fortunes: Democratic Institutions and Foreign Direct Investment Inflows to Developing Countries", International Organization, Vol.57, ss.175- 211.

Lucas, Robert (1988), "On the Mechanics of Economic Development”, Journal of Monetary Economics, Vol.22, No.1, ss. 3-42.

Masron, Tajul Ariffin ve Nor, Eliza (2013), “FDI in ASEAN-8: Does Institutional Quality Matter?”, Applied Economics Letters, Vol. 20, No. 2, ss. 186-189.

North, Dauglas ve Thomas, Robert P. (1973), The Rise of the Western World: A New Economic History, Cambridge University Press, Cambridge, UK. 
North, Douglass C. (1990), Institutions, Institutional Change and Economic Performance, Cambridge: Cambridge University Press.

OECD (2002). Foreign Direct Investment for Development: Maximising Benefits, Minimising Costs. http://www.oecd.org/dataoecd/47/51/1959815.pdf (Erişim tarihi: 21.01.2015)

Pesaran, Hashem ve Shin, Yongcheol (1999), "An Autoregressive Distributed-Lag Modelling Approach to Cointegration Analysis”, (Edt. Steinar Storm), Econometrics and Economic Theory in the 20th Century: the Ragnar Frisch Centennial Symposium, Cambridge: Cambridge University Press, ss. 371-413.

Pesaran, Hashem, Shin Yongcheol ve Smith Richard (2001), "Bounds Testing Approaches to the Analysis of Level Relationship", Journal of Applied Econometrics, Vol.16, No.(3), ss. 289-326.

Phillips, Peter ve Perron Pierre (1988), “Testing for a Unit Root in Time Series Regression”. Biometrica, Vol.75, No.2, ss. 335-346.

Romer, Paul M. (1986), "Increasing Returns and Long-run Growth”, Journal of Political Economy, Vol.94, No.5, ss. 1002-1037.

Romer, Paul M. (1990), “Endogenous Technical Change”, Journal of Political Economy, Vol. 98, ss. 71-102.

Schneider, Friedrich ve Frey, Bruno (1985), "Economic and Political Determinants of Foreign Direct Investment", World Development, Vol.13, No.2, ss. 161-175.

Smarzynska, Beata (1999), Composition of Foreign Direct Investment and Protection of Intellectual Property Rights in Transition Economies, Centre for Economic Policy Research (CEPR) Working Paper.

Solow, Robert M. (1956), “A Contribution to the Theory of Economic Growth", Quarterly Journal of Economics, Vol.70, No.1, ss. 65-94.

Stein, Ernesto ve Daude, Christian(2001), "Institutions, Integration and the location of Foreign Direct Investment", OECD conference New Horizons and Policy Challenges for Foreign Direct Investment in the 21st century, Mexico, November.

Uğur, Mehmet (2011), “Kurumsal Kalite ve Ekonomik Performans: İktisadın (Yeniden) Syasallaşması Mı?”, İktisat ve Toplum, Vol. 1, Sayı. 9, ss. 36-41.

Wei, Shang-Jin (1997), How Taxing is Corruption on International Investors?, NBER Working Paper No. 6030.

Wei, Shang-Jin (2000), "How Taxing is Corruption on Internal Investors?", Review of Economics and Statistics, Vol. 82, No.1, ss. 1-11.

Wheeler, David ve Mody, Ashoka (1992), "International Investment Location Decisions. The Case of U.S. Firms", Journal of International Economics, Vol.33, No.1-2, ss.57-76.

Zivot, E. ve Wang, Jiahui (2006), Modelling Financial Time Series with S-PLUS, Second Edition. Springer Publishing. 